\title{
Stage IVA Thyroid Gland Anaplastic Carcinoma AJCC v8
}

National Cancer Institute

\section{Source}

National Cancer Institute. Stage IVA Thyroid Gland Anaplastic Carcinoma A/CC v8. NCI

Thesaurus. Code C141001.

Stage IVA includes: T1-T3a, N0/NX, M0. T1: Tumor measuring $2 \mathrm{~cm}$ or less in greatest dimension limited to the thyroid. T2: Tumor measuring more than $2 \mathrm{~cm}$ but $4 \mathrm{~cm}$ or less in greatest dimension limited to the thyroid. T3a: Tumor measuring more than $4 \mathrm{~cm}$ in greatest dimension limited to the thyroid. N0: No evidence of locoregional lymph node metastasis. NX: Regional lymph nodes cannot be assessed. M0: No distant metastasis. (from AJCC 8th Ed.) 